\title{
A CONSTRUÇÃO DA IMAGEM DO DIABO NA LITERATURA INFANTIL: UMA LEITURA DO CONTO “O BOM DIABO”, DE MONTEIRO LOBATO
}

Yvonélio Nery Ferreira ${ }^{2}$

Marília Simara Crozara ${ }^{3}$

- “Lúcifer! Satanás!..."

Só outro silêncio. O senhor sabe o que o silêncio é? É a gente mesmo, demais.

- “Ei, Lúcifer! Satanás, dos meus Infernos!”

Voz minha se estragasse, em mim tudo era cordas e cobras. E foi aí. Foi. Ele não existe, e não apareceu nem respondeu - o que é um falso imaginado. Mas eu supri que ele tinha me ouvido. Me ouviu, a conforme a ciência da noite e o envir de espaços, que medeia. Como que adquirisse minhas palavras todas; e fechou o arrocho do assunto.

Guimarães Rosa

\section{ACERCA DA LITERATURA INFANTO-JUVENIL:}

Pensar a literatura infanto-juvenil é refletir sobre a evolução da família burguesa e o status adquirido pela criança na sociedade e no âmbito doméstico no decorrer desse percurso. É questionar o modo como a esta literatura foram atribuídas características de inferioridade se comparada à literatura geral. É indagar acerca das funções iniciais de sua origem e as que a ela hoje são destinadas.

O papel exercido pela criança no seio da família não é o mesmo ao longo da história. Na Idade Média, a organização familiar estava pautada no sistema de linhagens e clientela, atrelada à estrutura feudal, buscando a preservação da propriedade e a transmissão de heranças. Para tanto, o casamento representava um dos principais instrumentos de manutenção desse sistema, fazendo com que fosse recorrente a exclusão dos laços afetivos, para se atender aos anseios de um grupo. Exclui-se, desse

\footnotetext{
${ }^{1}$ Uma versão deste texto foi publicada no livro Escritos luciféricos, em 2014, e, depois de algumas revisões e alterações, foi submetido a esta publicação.

${ }^{2}$ Professor Adjunto II da área de Teoria Literária e Literaturas de Língua Portuguesa, da Universidade Federal do Acre, Centro de Educação e Letras, Campus de Cruzeiro do Sul e do Programa de Pós-graduação em Letras: Linguagem e Identidade (mestrado), da Universidade Federal do Acre, Campus de Rio Branco.

yvoneryferreira@gmail.com

${ }^{3}$ Doutoranda em Estudos Literários - Programa de Pós-graduação em Estudos Literários: Mestrado e doutorado, da Universidade Federal de Uberlândia. mariliascrozara@yahoo.com.br
} 
processo, as noções de privacidade e de vontade individual: o chefe da família guiava a criança a partir de seus interesses, demonstrando, assim, a falta de laços afetivos entre pais e filhos.

Nesse contexto, às crianças não era destinada nenhum tipo de atenção específica por parte dos pais, que, por vezes, as tratavam como iguais, fazendo-as participar de modo igualitário da vida adulta. Estavam presentes no trabalho, nas festas, nas guerras, nas execuções, dentre outros eventos, compartilhando de todos os momentos naturais da existência humana. As crianças eram constantemente negligenciadas, tratadas com brutalidade e hostilidade, decorrendo dessa atitude os altos índices de mortalidade infantil.

A presença constante das amas de leite exemplifica o descaso dos pais para com seus filhos. Elas eram, muitas vezes, as únicas responsáveis pela manutenção alimentar e educacional das crianças nos primeiros anos de vida. Ou seja, esse papel não era reservado à mãe, que só tomou para si a função materna no século XVII, quando ocorrem mudanças profundas na estrutura familiar, propiciando a elevação da mulher no ambiente doméstico.

O século XVII marca, pois, o fim de inúmeras condutas seguidas na Idade Média. Com a centralização do poder nas mãos de um governo absolutista, houve o enfraquecimento dos grupos de parentesco e a abolição do poder baseado no feudalismo. Foi o momento de ascensão do Estado Moderno e da burguesia como mantenedora desse estado a partir de uma aliança entre o poder político centralizador, a camada burguesa e o capitalismo, ocasionando o surgimento de uma nova ideologia familiar, erigida no individualismo, na privacidade e na promoção do afeto.

Houve, assim, segundo Regina Zilberman e Lígia Cademartori Magalhães (1974, p. 06), uma profunda mudança na organização familiar entre os séculos XVII e XVIII:

\footnotetext{
[...] no século 17, a organização é fortemente patriarcal e recebe grande influência e estímulo dos protestantes, já que os pastores viam a criança como um indivíduo que somente podia ser domado pela educação religiosa rígida, cabendo aos pais este papel de sujeição da vontade infantil; no século 18, os pequenos e as mulheres gozam de maior liberdade, de modo que a família exibe a imagem de uma parceria interna, dominada pelo liberalismo e calor afetivo, e não pelo poder paterno e a obediência hierárquica.
}

Foi, portanto, somente no século XVIII que ocorreu uma verdadeira valorização da infância, e as crianças passaram ao cerne das observações. Eram vistas como um grupo de caráter especial, diferente dos adultos, com características individuais. Para tanto, necessitavam de tratamento 
diferenciado, o que desencadeou a criação de instituições especializadas, como as escolas, responsáveis pela inserção social e pela união entre as crianças e o mundo.

Nesse contexto burguês e absolutista, a família foi reestruturada, rompendo com a visão familiar adotada na Idade Média. “A criança burguesa encontra-se plenamente integrada no contexto familiar, uma vez que este foi solidificado para resguardá-la" (ZILBERMAN e MAGALHÃES, 1974, p. 09). Com isso, o agente dessa proteção passa a ser a personagem materna, ocasionando uma ascendência da mulher na organização doméstica. Vale ressaltar, no entanto, que o papel da mulher restringia-se à vida doméstica, pois, fora dela, continuava excluída da esfera pública, espaço reservado ao homem.

O surgimento da Literatura Infantil está intimamente ligado a esse processo de ascensão da família burguesa e à mudança de tratamento dado às crianças. A nova organização familiar necessitava de uma expressão literária específica para seus filhos, que precisavam se (in)formar. Em decorrência das exigências desse tempo, há um caráter pedagógico na origem da produção literária destinada à criança.

O caráter formador da literatura infantil vinculou-a, desde a sua origem, a objetivos pedagógicos, que por muito tempo silenciou no texto questões relativas à sexualidade, ao racismo, à segregação das mulheres e a outras mazelas da sociedade e de seus jogos de poder. Era um discurso monológico que não abria brechas para interrogações, para o choque de verdade, para o desafio de diversidade.

No entanto, além dos objetivos pedagógicos comprometidos com a legitimação das instituições, costumes e crenças que a geração adulta quer legar à infantil, a literatura propicia à criança uma reorganização de suas percepções do mundo, a aquisição de experiências existenciais, a formação de novos padrões e o desenvolvimento do senso crítico.

Quando se pensa no adjetivo "infantil", que acompanha o substantivo "literatura", particulariza-se essa literatura em função do destinatário estipulado: a criança. Trata-se de um tipo de texto destinado à criança e lido por ela, mas escrito por um adulto. Mesmo estabelecendo essa relação de um ser que domina, o adulto, e um que é dominado, a criança, em termos de escrita e leitura, a literatura infantil se configura não só como instrumento de formação conceitual, mas também de emancipação da manipulação da sociedade. A literatura surge, pois, como um meio de superação da dependência e da carência por possibilitar a reformulação de conceitos e a autonomia do pensamento. 
Consagrada pelo público mirim de diferentes épocas, a literatura infantil tem como parâmetro a obra de Charles Perrault ${ }^{4}$, que, no século XVII, coletou contos e lendas da Idade Média, adaptandoos em seus famosos contos de fadas. No século XIX outra coleta de contos foi realizada pelos irmãos Grimm, por Christian Andersen. Além deles, outros importantes nomes da literatura infantil são Collodi, Lewis Carrol, Frank Baum, dentre outros.

No Brasil, especificamente, a literatura infantil inicia-se sob a égide de um dos mais destacados intelectuais: Monteiro Lobato, que prestigia o gênero, mas, ao mesmo tempo, faz com que a literatura infantil brasileira vivesse à sombra de seu nome. O escritor brasileiro, formado pelo pensamento europeu, via seu país de fora. Com isso, processa-se, em virtude da formação histórica de Lobato, uma confluência cultural, em que, ao nativo, se acrescenta o pensamento estrangeiro. Desenvolve-se, por isso, dois tipos de cultura no Brasil: uma europeia, elitista, livresca; outra popular, nativa, ágrafa.

Monteiro Lobato concilia, assim, o que é tipicamente brasileiro com as inevitáveis contribuições da cultura estrangeira. Suas produções infantis criam um mundo que não se constitui num reflexo do real, mas na antecipação de uma realidade que supera os conceitos e os preceitos da situação histórica em que é produzida.

Em outra perspectiva, nota-se que o esforço de compreensão crítica do passado permite, em suas histórias, um redimensionamento do presente que, por sua vez, torna possível a prospecção, ou seja, o olhar para o futuro. Hans Robert Jauss (1994) postula que o leitor é uma força histórica e criadora, de modo que a obra pode ser apreciada a partir do papel ativo que ela possibilita a seu destinatário. A leitura de textos poéticos à criança em fase de alfabetização, por exemplo, não só aproxima o livro como fonte de conhecimento e de prazer, como exerce papel importante na formação da expressão verbal.

A narrativa que descreve um perigo iminente ameaçando as personagens não faz com que a criança se esconda. Essa independência entre o que é percebido e a ação é fruto de um longo processo de desenvolvimento do leitor. As ações narradas são concebidas no imaginário, onde habitam figuras recorrentes, como fadas, príncipes, princesas, reis, rainhas, seres mitológicos, animais falantes e, até mesmo, o Diabo. Aliás, essa figura aparece de forma variada em diversos textos destinados ao público infantil.

\footnotetext{
4 Vários fatores na obra de Charles Perrault são apontados como elementos básicos da literatura infantil, como a preocupação com o didático e a relação com o popular. A análise dos contos de Perrault requer um enfoque interdisciplinar, por suscitar problemas que não se restringem à teoria da literatura, à sociologia, à psicanálise ou ao folclore, mas à união desses enfoques.
} 
Diante disso, pretende-se observar como a imagem do Diabo aparece no conto "O bom diabo", presente na obra Contos da Tia Nastácia, de Monteiro Lobato (1995). Para tanto, antes da abordagem sugerida, faz-se necessário alguns breves apontamentos a respeito da forma como se construiu o imaginário da figura do Diabo na cultura ocidental, baseando-nos, sobretudo, nos pressupostos teóricos de Gerald Massadié (2001), em História geral do Diabo: da antiguidade à idade contemporânea, e de Carlos Roberto F. Nogueira (2000), em O Diabo no imaginário cristão.

\section{O DIABO: PELA CONSTRUÇÃO DE UM IMAGINÁRIO}

No prefácio do livro História geral do Diabo: da antiguidade à idade contemporânea, Gerald Messadié apresenta, de forma irônica, inúmeras referências feitas ao Diabo, a começar por sua participação política, uma vez que várias autoridades atribuíam e ainda atribuem características de Satanás a outros políticos. Além disso, há uma banalização da imagem do Diabo, presente nas ameaças feitas a crianças, remetendo ao caráter fantástico, fabular e irreal dessa personagem.

Personificação do mal, o Diabo é, no entanto, posterior às ideias da maldade e da tentação. Segundo o Antigo Testamento, ${ }^{5}$ Deus, criador do bem e do mal, deveria ter o seu simétrico, para que não lhe fossem atribuídos os males da humanidade. É como se participássemos de uma guerra incessante contra o Mal, que sustenta um grande fanatismo e exerce uma influência política e religiosa considerável nas pessoas.

A história judaico-cristã começa com uma perda, a do paraíso, já aludindo para as possíveis interferências do Diabo, invejoso da criação de Deus. No entanto, o livro do Gênesis apresenta várias contradições no que se refere à serpente e à perda do paraíso, pois, segundo o relato bíblico, Adão e Eva não sabiam o que era o Mal antes de experimentarem o fruto proibido, cujo pecado foi o ato sexual (o que seria inevitável, estando eles nus no paraíso).

Há outros pontos falhos na Bíblia como o fato de o Senhor ter criado a serpente e não tê-la castigado por seu ato tentador. No A. T., Deus brinca com seu poder de criação e destruição: há várias passagens em que Ele resolve extirpar suas criaturas da face da terra. Toda a criação paga, assim, pela decepção de Deus, alheio a qualquer noção de perdão.

Observa-se que em várias passagens do A. T. (Gênesis, Livro de Jó, Livro de Isaías, entre outros), a figura do Diabo é extremamente fraca e banal; o anjo caído estava longe de ser o rebelde

\footnotetext{
${ }^{5}$ Para referências ao Antigo Testamento será utilizada a abreviação A.T.
} 
infame com comissuras nos lábios, o inimigo confesso de Deus. O Judaísmo, por exemplo, não representou nem os demônios nem Satanás como inimigos de Deus, mas como servidores e aliados.

Em outros momentos, o Diabo parece agir por conta própria, como em As Crônicas. Deus é, no A. T., o Bem e o Mal, e o Diabo seu servidor. No Livro de Henoc, ${ }^{6}$ os demônios são anjos que não se rebelaram contra Deus, mas que se apaixonaram por mortais e desceram à Terra para se unirem a eles. Tal fato, entretanto, contradiz os outros livros do A. T. Presente na tradição judaica, o Diabo foi ressignificado pelo Cristianismo no Novo Testamento, ${ }^{7}$ transformando-o em símbolo de malevolência.

A partir da Grande Crise do Judaísmo, o Diabo foi redefinido como o inimigo confesso de Deus, e a divisão do mundo ocidental foi consumada pelo embate entre Deus e o Diabo, o bem e o mal. Essa dicotomia não foi, entretanto, uma invenção judaica: os judeus inspiraram-se no Mazdeísmo, religião fundada na antiga Pérsia pelo profeta Zoroastro, que, no século VI antes da era cristã, já considerava o dualismo Deus-Diabo. A partir de então, a figura do Diabo como personificação do mal teria assegurada uma longa vida.

Massadié ainda ressalta a passagem do N. T. em que, após o seu batizado, Jesus foi tentado pelo Demônio. O batizado de Jesus é, no entanto, inútil e blasfematório, uma vez que ele fora concebido pelo Espírito Santo, e o batismo cristão destinava-se à redenção da falta original, ausente em Jesus. A tentação é também apresentada de forma contraditória em alguns Evangelhos: Deus reserva a seu próprio filho uma provação, assim como a Jó; Satanás é ignorante, pois sabe que Jesus é filho de Deus e não adiantaria tentá-lo; os milagres de Jesus destinam-se a seus discípulos, mas nunca ao Diabo.

Por intermédio de Jesus, a partir dos ensinamentos dos ascetas de Quoumrân, ${ }^{8}$ o Diabo, não o Satanás do Judaísmo do A.T., será transmitido ao Cristianismo. Retoma-se a ideia do essenismo: o advento do Diabo, em contraposição à imagem de Deus, acelera o fim dos tempos, o Apocalipse. No N.T., o Diabo aparece por meio de possessões violentas, e Jesus é o responsável por expulsar esses demônios. Além disso, o Diabo é comparado à doença, sendo caracterizado como espírito sujo.

\footnotetext{
${ }^{6}$ Livro apócrifo não incluído no cânon da Bíblia Judaica, nem no Antigo Testamento, nem nos livros deuterocanônicos. Contendo profecias e revelações, o livro foi supostamente escrito por Henoc, ancestral de Noé.

${ }^{7}$ Para referências ao Novo Testamento será utilizada a abreviação N.T.

${ }^{8}$ Constituíam um grupo ou seita judaica que existiu, provavelmente, entre 150 a.C. e 70 d.C. A partir da imitação simbólica dos sacerdotes antigos, buscavam aprender sobre a vida dos que vivem em isolamento, algo que, posteriormente, se tornaria característica da tradição monástica cristã.
} 
Observa-se, então, que, no A.T., os atos de Satanás têm motivo, mas, no Novo, ele se comporta com ações erráticas em diversos episódios.

A Igreja determinou, portanto, a genealogia do Mal, afirmando que Satanás é o chefe da força das trevas, que teria se revoltado contra Deus e arrastado anjos inferiores. A partir de então, surgem várias versões sobre a queda do Diabo e dos anjos. Diferentemente do A.T., pois, se Satanás existiu desde sempre e se foi contemporâneo da criação, já não há necessidade de fazer intervir a hipótese da sua queda. Em vários momentos, como no Livro de Jó, Deus e o Diabo estariam em pé de igualdade.

Enquanto para o Judaísmo, o Diabo não é uma figura de grande relevo; para o Cristianismo, o papel de Satanás é imprescindível para que haja a ideia de Redenção. A Igreja teve, portanto, que disseminar a imagem do Diabo, gerando como consequência diversas questões não resolvidas: de onde vinha Satanás? como surgiu o mal? Desconsiderando essas questões, Satanás foi supervalorizado com o objetivo de alavancar o Cristianismo.

Carlos Roberto F. Nogueira, em O Diabo no imaginário cristão, deixa clara a importância vital do papel desempenhado pelo demônio e seus agentes, afirmando que eram necessárias, para a coletividade cristã, a existência e a encarnação do Mal; só assim o Bem surgiria como graça suprema. A história do Diabo confunde-se, assim, com a história do próprio Cristianismo.

O nascimento do Cristianismo inicia um longo processo em que as tradições chocam-se, interpenetram-se, amoldam-se, para repelir e revestir o Diabo com toda uma bagagem mística que convive paralelamente ao corpo doutrinário oficial. A demonologia que aparece nos textos apócrifos é retomada de forma ligeiramente modificada no N. T., quando Satã passa a ser visto como o grande adversário, tendo por missão combater a religião que acaba de nascer. Satã será o inimigo implacável de Jesus e seus discípulos. O universo inteiro passa a ser pintado como dividido entre dois reinos, o de Cristo e o do Diabo. Pouco a pouco, o Espírito do mal passa a integrar o dogma central do cristianismo, o da queda do homem, do pecado original e da redenção pela morte do Messias na cruz. Contudo, não há na mentalidade dos cristãos dos primeiros tempos a mesma fascinação mórbida que povoará de fantasmas demonolátricos os teólogos da Baixa Idade Média.

Enquanto o Paganismo ainda teve força social, o homem da Igreja dialogou e argumentou em favor de suas crenças visando converter os povos que não conheciam o Cristianismo ou a ele resistiam. Quando a cristianização foi absoluta e a autoridade eclesiástica teve o poder a seu serviço, a postura mudou. $\mathrm{O}$ mundo passou a se dividir em duas partes claramente definidas e antagônicas: a constituída pelos que cultivavam o Bem e as virtudes e aquela formada pelo Mal e seus vícios. 
Os primeiros séculos da Idade Média representam um mundo em conflito entre a mais alta espiritualização e a mais grosseira crueza mundana. O homem é personagem de um drama que tem sua origem na trágica dicotomia entre o representado e o vivido, não podendo pensar no Bem sem antes pensar no Mal.

Em meio a tudo isso, começa-se a ser elaborada, nas consciências cristãs, a ideia de sociedades secretas de adoradores do diabo. A angustiante preocupação com o poder de Satã e suas cortes leva os homens da Igreja a identificar no seio da comunidade cristã aqueles que concorrem para aumentar o poder maligno. O Diabo torna-se mais respeitado e poderoso do que nunca. Fazem-se pactos com ele, nos quais homens entregam suas almas em troca da satisfação de qualquer tipo de desejo. Satã torna-se o Grande Destruidor, o arqui-inimigo, dotado de numerosos e apavorantes poderes, diante dos quais o homem está indefeso, a não ser pelos avisos de Deus e a constante ajuda dos ministros da Igreja.

A presença constante do Diabo faz surgir uma nova linha de especulação, com a autoridade de uma ciência - a demonologia. Os teólogos passam a estabelecer o perfil de caráter dos adorados de Satã, num esforço para auxiliar a Cristandade a reconhecer o Inimigo e se precaver contra ele.

Nesse contexto de disseminação do medo e para reiterar a imagem maligna do Diabo, ele foi representado como um animal ou mesclado de formas humanas e animais, salientando sua natureza bestial. O grande modelo que influenciou toda uma iconografia diabólica foram as clássicas imagens de Pã e dos sátiros.

No fim da Idade Média os demônios povoaram o mundo em profusão, e vários teólogos e filósofos buscaram classificá-los numericamente. Assim, o Reino do Diabo aparecia como uma vasta e organizada monarquia presidida por Satã e secundada por príncipes, duques, marqueses, condes e prelados. Mas a ameaça cotidiana do Maligno trazia consigo um outro terror, o da aparição de um outro monstro do Mal: o Anticristo.

O Anticristo era a contrapartida maligna do Cristo. Um representado por toda bondade e luz, o outro, maldade e escuridão; um nascido de uma virgem, o outro de uma prostituta. A crença incorpora-se ao Cristianismo, e seus adeptos passam a afirmar que o retorno de Jesus em toda a sua glória e majestade seria precedido pelo homem do pecado, o filho da perdição. A palavra Anticristo apareceu no N. T., nas epístolas de João, e era usada para atacar desvios doutrinários dentro do rebanho cristão.

No início da Modernidade, a Europa ocidental é marcada por um incrível medo do Diabo. O Renascimento herdou os conceitos e imagens demoníacas que foram determinados e multiplicados 
no decorrer da Idade Média, mas lhes emprestou uma coerência, uma importância e uma difusão jamais alcançadas, a exemplo de sua presença predominante nos discursos religiosos, muito maior do que a de Deus. Medo que estava associado à espera do fim do mundo: a ferocidade alucinante do Demônio se explica pela proximidade da catástrofe final.

No entanto, o Romantismo transformará o Demônio no símbolo do espírito livre, da vida alegre, não contra uma lei moral, mas segundo uma lei natural, contrária à sua aversão, pregada pela Igreja. Satanás significava liberdade, progresso, ciência e vida. O demoníaco era sinal de paixão. Com isso, a partir de 1850, o ocultismo experimentou um grande florescimento, derivado diretamente da exaustão do otimismo liberal. Essa discussão pode ser percebida na obra $O$ Fausto, do filósofo alemão Goethe. No contexto brasileiro, essa alusão romanesca da demonologia e do fantasmagórico está na obra Macário, de Aluísio de Azevedo.

Já no século XX, a geração do sexo, drogas e rock n' roll trará em seu amadurecimento uma extraordinária revivescência do ocultismo, atingindo seu clímax no período 1968-1973. Várias foram as seitas e os rituais praticados em nome do Diabo. Da década de 1960 em diante, houve um desenvolvimento constante das seitas exotéricas e do satanismo a partir de inúmeras vertentes.

Essas rápidas explanações baseadas nos textos de Massadié e Nogueira buscaram demonstrar, historicamente, o modo como o Diabo foi inserido no imaginário cristão e, por consequência, no imaginário ocidental, influenciando, também, sua produção literária, uma vez que o Diabo torna-se figura constantemente retomada em diversos textos, tanto aqueles destinados a adultos, quanto os infantis, como observaremos a seguir, por meio da leitura de "O bom diabo", de Monteiro Lobato (1995).

\section{SIM, UM BOM DIABO!}

Conforme Alfredo Bosi (2001, p. 216), Lobato, além de crítico de Anita Malfatti e do Movimento Modernista de 1922, também “[...] encarnou o divulgador agressivo da Ciência, do progressismo, do 'mundo moderno', tendo sido um demolidor de tabus, à maneira dos socialistas fabianos, com um superávit de verve e de sarcasmo." Será, pois, desse lugar irreverente da arte lobatiana que pontuaremos a importância de questões como a demonologia na sua literatura infantojuvenil.

A obra Contos da Tia Nastácia, publicada em 1937, corresponde a uma antologia de historietas populares narradas pela personagem título a pedido de Pedrinho e da boneca Emília. Na 
primeira parte dessas narrativas, o neto de Dona Benta solicita à boneca que questione a avó sobre o que seria folclore e, para essa questão, a menina de pano recolhe a seguinte resposta:

Dona Benta disse que folk quer dizer gente, povo; e lore quer dizer sabedoria, ciência. Folclore são as coisas que o povo sabe por boca, de um contar para o outro, de pais a filhos — os contos, as histórias, as anedotas, as superstições, as bobagens, a sabedoria popular, etc. e tal. (LOBATO, 1995, p. 51).

O esclarecimento de Dona Benta, sua percepção "cientificista" da cultura, leva Pedrinho a refletir sobre o saber popular, personificado pela própria tia Nastácia: “[...] Tia Nastácia é o povo. Tudo que o povo sabe e vai contando, de um para outro, ela deve saber. Estou com o plano de espremer tia Nastácia para tirar o leite do folclore que há nela.” (LOBATO, 1995, p. 51).

Assim como Sherazade conta as histórias de sua cultura árabe ao Sultão para delongar a própria vida, a negra Nastácia também o fará a Pedrinho e aos demais ouvintes, sob a égide didática do folclore brasileiro. Tia Nastácia ${ }^{9}$ desfia os contos populares aos moradores do sítio, que os interpelam e os criticam, tornando cada vez mais tensa a relação discursiva entre os apreciadores dos contos populares. É nessa moldura que se encontra a história “O bom diabo".

A narrativa de Nastácia aqui versa sobre a má sina do filho de uma rainha: morrer enforcado. Vendo a tristeza que assolava a família real, o jovem optou por isolar-se a fim de que tal fado não se cumprisse aos olhos dos seus. Tomada a decisão, o personagem apossou-se de uma soma de dinheiro para prover a viagem.

No caminho dessa peregrinação rumo ao seu destino, o príncipe deparou-se com uma capela de São Miguel em ruínas, havendo, nela, a imagem do santo e a do diabo. Ao providenciar a restauração do local, o príncipe pediu ao pintor que deixasse a imagem do diabo sem a reforma solicitada - o que não foi acatado pelo pintor.

O personagem continua o seu caminho e se abriga na casa de uma senhora idosa que, ao vêlo contar as divisas que possuía, julgou-o equivocadamente e o denunciou como um ladrão, motivo pelo qual o jovem foi preso e condenado à forca.

\footnotetext{
${ }^{9}$ A postura de Tia Nastácia assemelha-se ao narrador oral benjaminiano. Segundo o filósofo: "O conto de fadas ensinou há muitos séculos à humanidade, e continua ensinando hoje às crianças, que o mais aconselhável é enfrentar as forças do mundo mítico com astúcia e arrogância" (BENJAMIN, 1994, p.215). Tia Nastácia conta histórias do folclore brasileiro ou adapta histórias tradicionais da cultura europeia revestidas de cores locais a fim de entreter e aconselhar seus personagens, na mesma direção, seus leitores. Tal processo vale-se de uma releitura do ritual das narrativas orais em que os ouvintes sentavam-se à beira de uma fogueira para ouvirem histórias e trocarem experiências.
} 
No dia da execução da sentença, continua Tia Nastácia, o anjo São Miguel chama a atenção do diabo, visto que ele não fora ter para com aquele que o prestigiara:

— Então, estás agora bonito, hein diabo?

— É verdade. Pintaram-me inteirinho.

— E não sabes quem consertou esta capela e nos pintou?

O diabo não sabia; o santo contou-lhe a história do príncipe que passara por ali, e disse mais que esse pobre moço fora preso, processado e julgado, e naquele mesmo dia ia ser erguido a uma forca por causa das intrigas de certa velha (LOBATO, 1995, p.51).

Ao mesmo tempo em que o Santo pode ser visto sob a ótica da dessacralização no que tange à delação da velha, atitude advinda do convívio com o demônio, também pode ser enunciado como uma das representações simbólicas do Arcanjo no discurso cristão. Parafraseando Chevalier em seu Dicionário de Símbolos (2002, p. 84), S. Miguel é um dos arcanjos que simbolizam o juízo final, a justiça divina. Na iconografia cristã, um dos elementos representativos de sua figura corresponde à balança, ilustrativa da pesagem quanto ao merecimento justo das almas.

A despeito, porém, do que reza o senso comum (e cristão?), é o diabo quem resolve a situação do jovem preso injustamente. Lobato, dessa maneira, leva a personagem periférica a um patamar de superioridade:

\begin{abstract}
O diabo não quis ouvir mais. Pulou num cavalo e foi voando à casa da velha; agarrou-a e levoua ao rei, fazendo-a confessar toda a sua maquinação contra o moço. O rei deu ordens para que soltassem o preso e o trouxessem à sua presença.

O diabo montou no cavalo e voou para a prisão onde o príncipe ia ser enforcado, e apresentou ao carrasco a ordem de soltura. O carrasco entregou-lhe o condenado, que lá se foi com o diabo para o palácio do rei (LOBATO, 1995, p.52).
\end{abstract}

Descobre-se, assim, por meio da atitude do bom diabo, a denunciação caluniosa ${ }^{10}$ da mulher. Essa atitude justa do diabo, impedindo as maquinações da velha, pode ser entendida como o que Dona Benta chama de "o amansar da maldade", ao que Pedrinho atribui às descobertas darwinistas:

\footnotetext{
${ }^{10}$ A título de esclarecimento, entendemos que, na denunciação caluniosa, “[...] o agente, além de atribuir, falsamente, à vítima a prática de um delito, leva ao conhecimento da autoridade, mediante o delatio criminis, o fato, provocando a
} 
— Pois gostei! — gritou Emília. — Está aí uma historinha que descansa a gente daquelas repetições das outras. E mais que tudo gostei da camaradagem entre o santo e o diabo.

— Sim — disse dona Benta. — Como os dois vivessem na mesma capela, sozinhos, acabaram em muito bons termos, como se vê na história. O diabo é o símbolo da maldade, mas até a maldade amansa quando em companhia da bondade. De viverem juntos ali na capelinha, o santo e o diabo se transformaram em amigos, e os bons sentimentos de um passaram para o outro.

— Influência do meio! — gritou Pedrinho, que andava a ler Darwin.

Narizinho confessou que gostava muito das histórias com o diabo dentro, e disse que todas elas confirmavam o dito popular de que o diabo não é tão feio como o pintam (LOBATO, 1995, p.52).

Tia Nastácia, a representante da sabedoria do povo, chama a atenção de Narizinho e dos demais ouvintes para a relação estabelecida entre o diabo e o animal utilizado para simbolizá-lo, o cão, reiterando a sua atribuição maligna, a despeito da atitude generosa para com o príncipe. Tal simbologia, porém, é questionada pela personagem Emília, que vê no animal as qualidades mais nobres:

— Mas isso é história, menina. História é mentira. O "cão" é "cão". Não muda de ruindade.

— Se o cão é cão, viva o diabo! — gritou Emília. — Não há animal melhor, nem mais nobre que o cão. Chamar ao diabo cão, é fazer-lhe o maior elogio possível (LOBATO, 1995, p.53).

Segundo Chevalier (2002), o simbolismo do cão pode ser entendido por meio dos aspectos antagônicos que o constitui, independente da cultura na qual ele se encontre. Entretanto, é uma figura surpreendente ao se pensar a representação do cão ou mesmo do lobo como uma forma esotérica de sabedoria na qual se visualiza o sacrifício como um meio de atingir a elevação espiritual.

Pensando em toda a construção de sentido elaborada durante a narrativa e na conclusão de tia Nastácia de que "cão" é "cão", estabelece-se "um silogismo elogioso" à figura do diabo, pois, assim como o cão está ligado aos cuidados e à companhia do percurso existente entre a vida e a morte, à sexualidade sensível, ao ciúme, ao caráter medicinal e à fidelidade que possui, o diabo também o está. Narizinho tem razão: o diabo não pode ser tão feio quanto o pintam. "Coisas" do folclore.

instauração de inquérito policial ou de ação penal em vão, haja vista que restará provado que a vítima [...] é inocente" (SIQUEIRA, 2006, p. 01). 
Tomemos, novamente, os dizeres de Tia Nastácia frente ao "causo" enunciado: "Mas isso é história, menina. História é mentira. O "cão" é “cão". Não muda de ruindade." As palavras da personagem lobatiana anunciam o caráter ficcional das histórias narradas, prevalecendo, para ela, o saber popular. Com efeito, após observarmos pontualidades quanto à origem da literatura infantil e da figura do Diabo presente no imaginário ocidental, pudemos constatar como o deslindar do conto de Lobato desconstruiu as imagens populares atribuídas ao diabo por meio do saber científico, visando, assim, formar crianças sem o medo imanente do demônio.

Nesse texto de Monteiro Lobato, que recupera as influências orais da narrativa à maneira de um trabalho artesanal, é possível dizer que o "amansar da maldade" e a desmitificação da bondade se compenetram, a partir da simetria entre São Miguel e o Diabo, levando-nos a pensar em que medida esses sentimentos constituem o ser humano e a sociedade ocidental.

Esse estudo da demonologia sob o escopo da literatura infantil em Lobato pontuou a imagem do cão como um dos aspectos da figura do Diabo, inserida tanto no imaginário cristão quanto no ocidental, o que nos permitiu vislumbrar o entendimento folclórico brasileiro dessa figura e da maneira como ela pode ser apresentada ao público infantil, seja pelo aspecto mítico mostrado por Tia Nastácia, seja pelo científico apontado por Pedrinho.

Mas são sempre histórias: ficções para ensinar a viver. Por meio dessas falsas verdades, adultos e crianças experimentam sua cultura, repensam seu lugar histórico e constituem um posicionamento reflexivo, questionando os saberes populares e os costumes circundantes.

\section{REFERÊNCIAS}

BENJAMIN, Walter. “O Narrador. Considerações sobre a obra de Nikolai Leskov.” In: Magia e técnica, Arte e política: ensaios sobre Literatura e História da cultura. $7^{\mathrm{a}}$ ed. São Paulo: Brasiliense, 1994.

BOSI, Alfredo. História concisa da literatura brasileira. São Paulo: Cultrix, 1983.

CADEMARTORI, Lígia. O que é literatura infantil. São Paulo: Editora Brasiliense, 1986.

CARVALHO, Bárbara Vasconcelos. A literatura infantil: visão histórica e crítica. São Paulo: Global, 1989.

CHEVALIER, Jean e Alain Gheerbrant. Dicionário de símbolos: mitos, costumes, gestos, formas, figuras, cores, números. $17^{\mathrm{a}}$ ed. Rio de Janeiro: José Olympio, 2002.

LOBATO, Monteiro. Histórias de Tia Nastácia. São Paulo: Editora Brasiliense, 1995.

MESSADIÉ, Gerald. História Geral do Diabo - Da Antiguidade à Época Contemporânea. Trad. Alda Sophie Vinga. Portugal: Europa-América, 2001.

NOGUEIRA, Carlos Roberto F. O diabo no imaginário cristão. Bauru, SP: EDUSC, 2000.

PALO, Maria José; OLIVEIRA, Maria Rosa D. Literatura infantil: voz de criança. São Paulo: Ática, 1992. 
SIQUEIRA, Julio Pinheiro Faro Homem de. A diferença entre calúnia e denunciação caluniosa. Jus Navigandi, Teresina, ano 11, n. 1079, 15 jun. 2006. Disponível em: <http://jus.uol.com.br/revista/texto/8520>. Acesso em: 28 ago. 2011.

ZILBERMAN, Regina; MAGALHÃES, Lígia Cademartori. Literatura infantil: autoritarismo e emancipação. São Paulo: Ática, 1974

\section{A CONSTRUÇÃO DA IMAGEM DO DIABO NA LITERATURA INFANTIL: UMA LEITURA DO CONTO "O BOM DIABO", DE MONTEIRO LOBATO}

RESUMO: Na obra Contos da Tia Nastácia, publicada em 1937, uma antologia de historietas populares narradas pela personagem título a pedido de Pedrinho e da boneca Emília, podemos observar o entrecruzamento dos discursos religioso e folclórico, científico e popular. Nesse livro, a criada negra desfia os contos populares aos moradores do sítio, os quais, com postura crítica e interpelativa, tornam cada vez mais tensa a relação discursiva das histórias populares ouvidas. Ao resgatar folclores e crenças, Lobato procura desmitificá-los. Assim, no conto "O bom diabo", o amansar da maldade e a relativização da bondade se compenetram a partir da simetria entre São Miguel e o Diabo, levando-nos a pensar em que medida esses sentimentos constituem o ser humano e a sociedade ocidental. Buscaremos, portanto, mostrar como se constituem os discursos religioso e folclórico na história infantil "O bom diabo", de Monteiro Lobato. Para isso, refletiremos sobre a formação da literatura infantil e sobre a construção do imaginário da figura do diabo na cultura ocidental.

Palavras-chave: Literatura infantil. Discurso religioso. Cultura brasileira. Monteiro Lobato.

\section{THE CONSTRUCTION OF THE DEVIL'S IMAGE IN CHILDREN'S LITERATURE: A READING OF THE STORY "THE GOOD DEVIL" BY MONTEIRO LOBATO}

ABSTRACT: In A Tales Nastácia, published in 1937, an anthology of popular comic stories narrated by the title character at the request of Pedrinho and the Emília doll, we can observe the intertwining of religious and folkloric, scientific and popular discourses. In this book, the black maid slips the folktales from the locals, who, with a critical and interpersonal posture, make the discursive relation of popular stories heard increasingly tense. By rescuing folklore and beliefs, Lobato seeks to demystify them. Thus, in the story "The Good Devil," the taming of evil and the relativization of goodness are compenetrated from the symmetry between Saint Michael and the Devil, leading us to think to what extent these feelings constitute the human being and Western society . We will try, therefore, to show how the religious and folkloric discourses are constituted in the children's story "The good devil", by Monteiro Lobato. For this, we will reflect on the formation of children's literature and on the construction of the imaginary of the figure of the devil in Western culture.

Keywords: Child Literature. Religious discourse. Brazilian culture. Monteiro Lobato

\section{LA CONSTRUCCIÓN DE LA IMAGEN DEL DIABLO EN LA LITERATURA INFANTIL: UNA LECTURA DEL CUENTO "EL BUEN DIABLO", DE MONTEIRO LOBATO}

RESUMEN: En la obra Cuentos de la Tía Nastácia, publicada en 1937, una antología de historietas populares narradas por el personaje título a pedido de Pedrito y de la muñeca Emilia, podemos observar el entrecruzamiento de los discursos religioso y folclórico, científico y popular. En ese libro, la criada negra desata los cuentos populares a los habitantes del sitio, los cuales, con postura crítica e interpelativa, hacen cada vez más tensa la relación discursiva de las historias populares escuchadas. Al rescatar folclores y creencias, Lobato busca desmitificarlos. Así, en el cuento "El buen diablo", el amansar de la maldad y la relativización de la bondad se compenetran a partir de la simetría entre San Miguel y el Diablo, llevándonos a pensar en qué medida esos sentimientos constituyen el ser humano y la sociedad occidental . Buscaremos, por lo tanto, mostrar cómo se constituyen los discursos religioso y folclórico en la historia infantil "El buen diablo", de Monteiro Lobato. Para ello, reflexionamos sobre la formación de la literatura infantil y sobre la construcción del imaginario de la figura del diablo en la cultura occidental.

PALABRAS-CLAVE: Literatura infantil. Discurso religioso. Cultura brasileña. Monteiro Lobato. 